\title{
Evaluation of Antibiotic Utilization Pattern During Acute Diarrheal Disease at Chefa-Robit Health Center, Kemissie, North East Amhara, Ethiopia
}

This article was published in the following Dove Press journal: Drug, Healthcare and Patient Safety

\section{Desye Misganaw \\ Kassaw Abtew}

Pharmacology and Toxicology Unit, Department of Pharmacy, College of Medicine and Health Science, Wollo University, Dessie, Ethiopia
Correspondence: Desye Misganaw Pharmacology and Toxicology Unit, Department of Pharmacy, College of Medicine and Health Science, Wollo University, P.O. Box II45, Dessie, Ethiopia

Email desyemisganaw@yahoo.com
Background: Despite the fact that the majority of the acute diarrheal diseases are viral in origin and self-limited, routine and injudicious antibiotic treatment is a common practice globally and more prevalent in Africa. Indeed, the irrational use of antibiotics has a detrimental effect on the issue of antibiotics resistance and associated healthcare costs. Accordingly, a health center-based cross-sectional study is mandatory and was conducted due to the common malpractice of antibiotics use.

Objective: The aim of this study was to evaluate the antibiotic use pattern in the treatment of acute diarrheal disease in Chefa-robit health center, Kemissie, Northeastern Ethiopia.

Methods and Materials: A retrospective cross-sectional study was conducted to evaluate the antibiotic utilization pattern for the treatment of acute diarrheal disease. Data was collected from 230 patients' record cards treated for acute diarrheal disease from January 2018 to December 2018 using structured questionnaires. The finding is presented using frequency distribution and percentages in tables as well as figures.

Results: Among the 230 patients, $49.60 \%$ were males and the rest were females. From the total, 172 of them were with watery type of diarrhea and 132 of them were prescribed antibiotics inappropriately out of which 77 were under 5 years. In addition, 27 patients were diagnosed with mucoid diarrhea and only eight of them were treated with antibiotics whereas 31 patients were with bloody type of diarrhea and 10 of them were not treated with antibiotics. Of the 230 cases, 161 (70\%) patients received different types of antibiotics, and co-trimoxazole, amoxicillin and ciprofloxacin were the most prescribed antibiotics.

Conclusion: The study revealed that there is a high level of inappropriate antibiotics use which may fuel the increased antimicrobial resistance and associated costs nationally as well as globally.

Keywords: acute diarrheal disease, antibiotics, antimicrobial resistance

\section{Background}

Diarrheal disease is one of the leading causes of mortality worldwide and world health organization (WHO) defines diarrhea as the evacuation of a minimum of three loose stools in 24 hours. Diarrhea is qualified as 'acute' when symptoms are new and have not been present for more than 14 days. ${ }^{1}$ Acute diarrheal infection is caused by viruses, bacteria, and, less often by parasites. In fact, viral infections are the most common and frequent cause of acute diarrhea and mostly manifested as mild and non-inflammatory diseases. ${ }^{2}$ On the other hand, bacterial infections, especially those which are the invasive type or with toxin-producing bacteria, are associated with inflammation and more severe disease type., ${ }^{2,3}$ With regard to 
common symptoms, vomiting is more indicative of viral illness whereas fever, tenesmus, and grossly bloody stool are characteristics of illness caused by the ingestion of a preformed bacterial toxin. Among the bacterial pathogens, Salmonella, Campylobacter, Shigella, and shiga toxin-producing Escherichia coli (entero-hemorrhagic) are the most common causes of acute inflammatory diarrheal syndrome. ${ }^{4,5}$

Because acute diarrheal disease is most often selflimited and caused by viruses, routine antibiotic use is not recommended for patients with non-severe, watery diarrheal disease type. Indeed, the first step to treating acute diarrhea is supportive therapy such as oral rehydration and zinc supplementation (in children), particularly in developing countries. ${ }^{6-8}$

Nonetheless, many literatures have been revealing that antibiotics are being used unduly for the treatment of acute diarrheal infections which raises the concern of antimicrobial resistance and related problems. ${ }^{1,6,8}$ The emergence of antimicrobial resistance remains to be an alarming problem and continue to be the cause for increased rates of morbidity and mortality as well as a greater risk of complications and economic burden. ${ }^{6,7}$ Antibiotic resistance kills an estimated 700,000 people each year worldwide, and some experts predict that number could rise to 10 million by 2050 if efforts are not made to curtail resistance. ${ }^{8}$ Besides, the issue of antimicrobial resistance highly relevant to the developing world as $35 \%$ of the total health budget is spent on antimicrobials. ${ }^{9}$

Accordingly, evaluation of the utilization pattern of antibiotics for infectious diseases such as acute diarrheal disease has a substantial contribution for the promotion of rational antibiotic use and thereby to limit the spread of antimicrobial resistance and associated health care costs. Therefore, this study was initiated and conducted in Chefa-robit Health Center (CHC) to evaluate the prescribing and usage patterns of antibiotics for the treatment of acute diarrheal disease.

\section{Methods}

\section{Study Area and Design}

Chefa-robit Health Center is found in Chefa-robit town in northeast Ethiopia, about $300 \mathrm{~km}$ from Addis Ababa, the capital of Ethiopia. A cross-sectional retrospective study was carried out on 230 medical cards of patients who were treated for acute diarrheal disease from January 2018 to December 2018. A structured questionnaire was developed based on the study objective to collect the necessary data and then every 2 nd card $(560 / 230, k=2)$ was selected. The pretest was done to evaluate the completeness of the questionnaires to $5 \%$ of the patient cards of similar health centers.

Sample size was determined by using the following formula;

$$
n=\frac{\left(Z_{1-} \alpha_{/ 2}\right)^{2} P(1-P)}{d^{2}}
$$

where

$\mathrm{n}$ is sample size

$\mathrm{Z}_{1-\alpha / 2}$ is the standard normal variable at (1- $\left.\alpha\right) \%$ confidence level and $\alpha$ (level of significance) was taken to be $5 \%(95 \%$ confidence level is used $=1.96)$

$\mathrm{P}$ is estimate of the prevalence rate for the population $(50 \%)$

$\mathrm{d}$ is the margin of sampling error tolerated (0.5)

Accordingly, the $\mathrm{n}$ value was calculated and was found to be about 384 .

$$
n=\frac{(1.96)^{2}(0.5)(0.5)}{(0.5)^{2}}=384
$$

The number of medical cards (population size, N) of patients who were treated for acute diarrheal disease from January 2018 to December 2018 was 560. Since the population size was less than $10,00(\mathrm{~N}=560)$, a reduction formula was utilized and the actual sample size was found to be about 230 .

\section{Data Processing and Analysis}

The study variables are the following: Antibiotics use pattern, sex, and age of the patient, stool characteristics, and duration of diarrhea. The finding is presented using frequency distribution and percentages in tables and figures. The collected data was analyzed using SPSS software version 23 .

\section{Results}

Among a total of 230 patient cards, 114 (49.6\%) of them were males and the rest, 116 (50.4\%), were females. Besides, 119 (51.7\%) of them were under five and 5 $(2.2 \%)$ were greater than 65 years old as shown in Table 1.

A review of patient cases showed that most of them, about $84 \%$, experienced the illness for 2 to 3 days as showed in Figure 1. Additionally, the results revealed that patients also experienced other associated symptoms, 
Table I Socio-Demographic Characteristics of Patients with Acute Diarrheal Disease at Chefa-Robit Health Center, Kemissie from January 2018 to December 2018

\begin{tabular}{|c|c|c|}
\hline & & Number (\%) \\
\hline \multirow[t]{2}{*}{ Sex } & Male & II (49.6\%) \\
\hline & Female & II 6 (50.4\%) \\
\hline \multirow[t]{4}{*}{ Age } & $<5$ year & 119 (5I.5\%) \\
\hline & $5-12$ years & 38 (16.5\%) \\
\hline & $12-65$ years & 68 (29.6\%) \\
\hline & $>65$ & $5(2.2 \%)$ \\
\hline
\end{tabular}

commonly vomiting and fever, along with their diarrheal illness as shown in Figure 2.

Regarding stool characteristics, around $86.5 \%$ of the patients were with non-bloody type of diarrhea (watery and mucoid) whereas $13.5 \%$ of cases were with an invasive bacterial infection type (bloody diarrhea) as depicted in Figure 3.

As patients' records showed, the number of antibiotics prescribed for single patients ranged from 0 to 2 drugs. Accordingly, about 161 (70\%) of cases received at least one antibiotic and $5 \%$ of the patients were prescribed a combination of two antibiotics (Figure 4). However, about $69(30 \%)$ of the cases received no antibiotics during the episode of diarrhea as described in Figure 4.

According to patients' record cards, cotrimoxazole was the most commonly prescribed drug (64\%) followed by amoxicillin (19.3\%) and then ciprofloxacin (Table 2). Moreover, metronidazole, doxycycline and ampicillin were the least prescribed drugs in combination with cotrimoxazole and ciprofloxacin as revealed in Table 2.

\section{$\%$ Duration of diarrhea since onset}

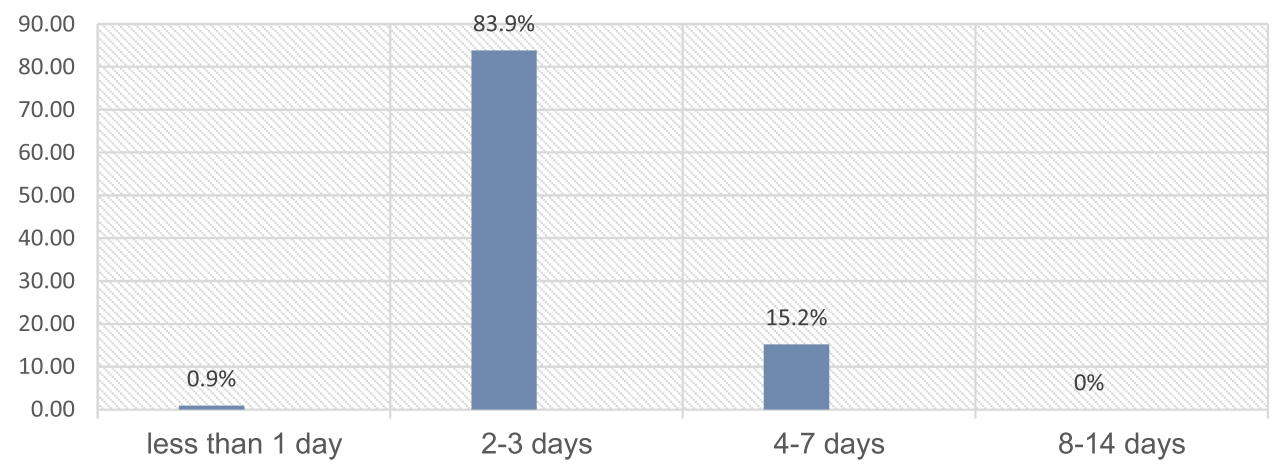

Figure I Duration of diarrhea from onset to treatment for patients diagnosed with acute diarrhea in Chefa-robit Health Center from January 2018 to December 2018.

\section{Number of Associated symptoms with diarrhea}

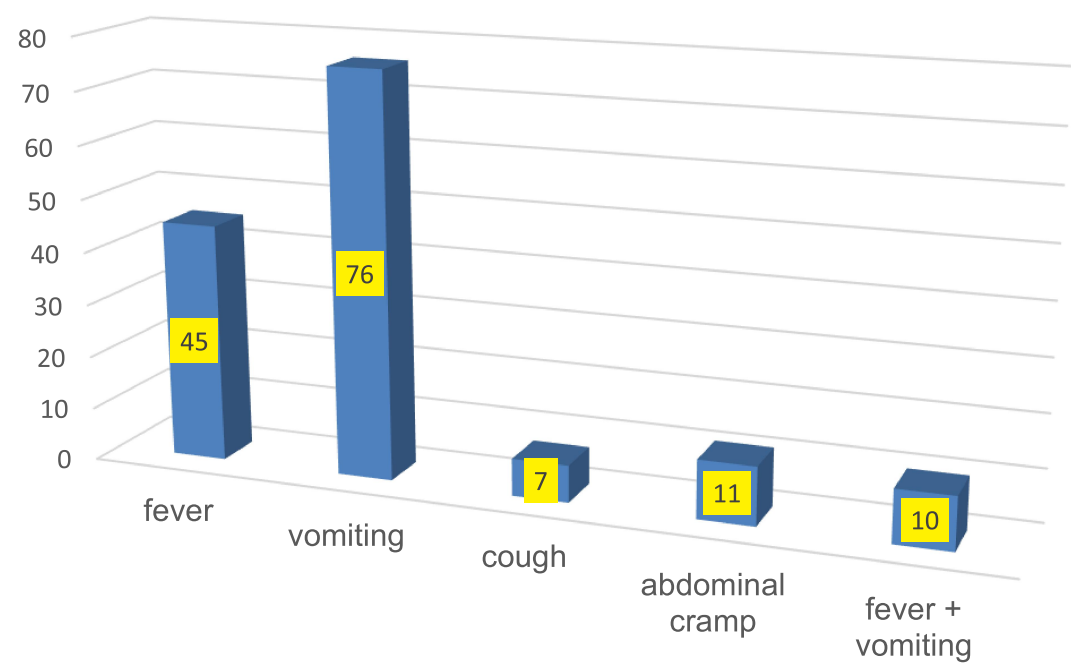

Figure 2 The number of associated symptoms for patients diagnosed with acute diarrhea in Chefa-robit Health Center from January 2018 to December 2018. 


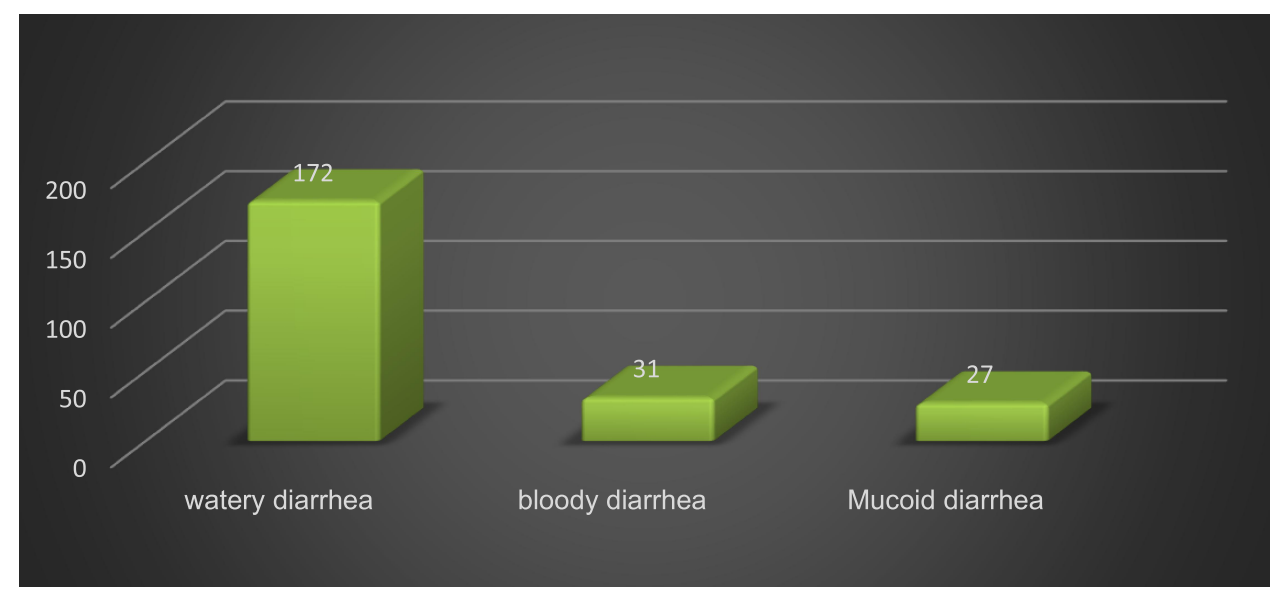

Figure 3 Stool characteristics for acute diarrhea patients in Chefa-robit Health Center from January 2018 to December 2018.

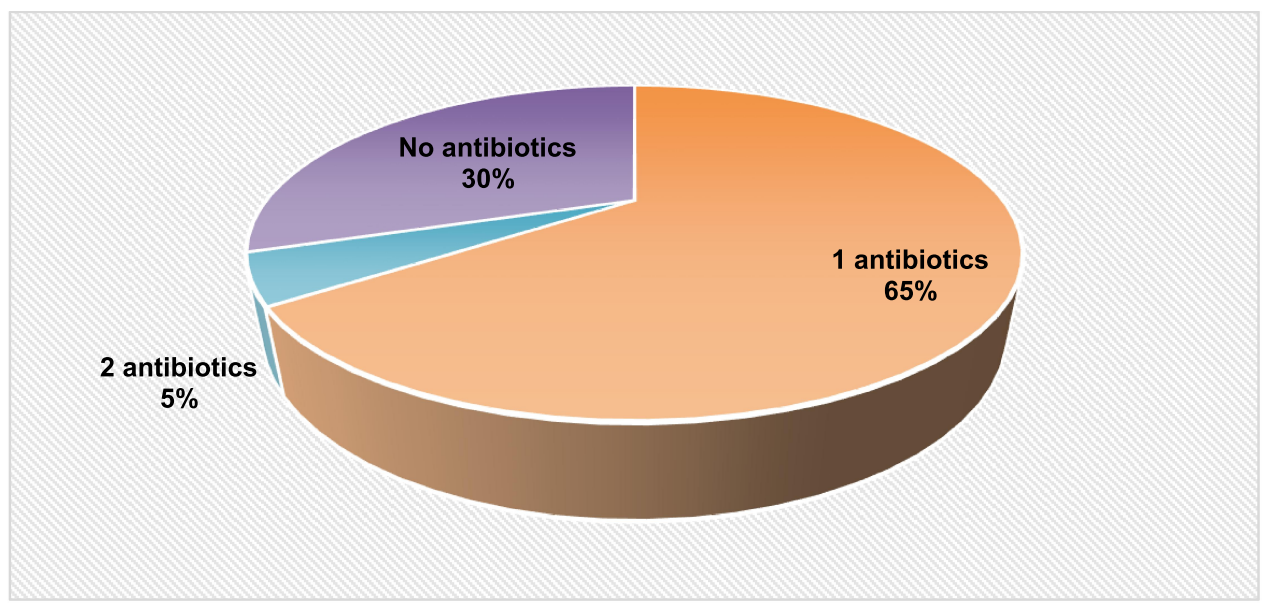

Figure 4 Number of antibiotics prescribed for each diarrheal patients in Chefa-robit Health Center from January 2018 to December 2018.

From the total, 172 of them were with watery type of diarrhea and 132 of them were prescribed antibiotics inappropriately out of which 77 were under 5 years. In addition, 27 patients were diagnosed with mucoid diarrhea and only eight of them were treated with antibiotics whereas

Table 2 Antibiotic Prescribed for Patients with Acute Diarrheal Disease at Chefa-Robit Health Center, Kemissie from January 2018 to December 2018

\begin{tabular}{|l|l|}
\hline Type of Antibiotics & Number (\%) \\
\hline Ciprofloxacin & $9(5.6)$ \\
Amoxicillin & $31(19.3)$ \\
Cotrimoxazole & $103(64)$ \\
Metronidazole & $7(4.3)$ \\
Metronidazole + Cotrimoxazole & $6(3.7)$ \\
Doxycycline + Ciprofloxacin & $3(1.9)$ \\
Ampicillin + Cotrimoxazole & $2(1.2)$ \\
\hline
\end{tabular}

31 patients were with bloody type of diarrhea and 10 of them were not treated with antibiotics as shown in Table 3.

\section{Discussion}

A review of the history of the cases showed that most of them experienced the illness for 2-3 days and vomiting and fever were the most common associated symptoms, probably suggesting infections of viral origin. ${ }^{5}$ Therefore, the use of antibiotics for community-acquired diarrhea should be discouraged since most of them were viral in origin as well as the disease progression is not shortened by the use of antibiotics. ${ }^{8}$ Moreover, empirical treatment should be avoided in patients presenting with bloody stools, because potential causes include Escherichia coli $\mathrm{O} 157$ or other strains producing Shiga-like toxin that could cause severe and invasive type of infection. ${ }^{10}$

Although $75 \%$ (172) of the total patients were with watery diarrhea, a type of self-limited diarrhea that does 
Table 3 Antibiotics Usage by Age Groups and Stool Characteristics with Acute Diarrheal Disease at Chefa-Robit Health Center, Kemissie from January 2018 to December 2018

\begin{tabular}{|c|c|c|c|c|c|c|c|c|c|c|c|}
\hline \multirow{3}{*}{$\begin{array}{l}\text { Age } \\
\text { Groups }\end{array}$} & \multicolumn{11}{|c|}{ Stool Type and Antibiotics Prescription Pattern } \\
\hline & \multirow[t]{2}{*}{$\begin{array}{l}\text { Watery } \\
\text { Diarrhea }\end{array}$} & \multicolumn{2}{|c|}{$\begin{array}{l}\text { Antibiotics } \\
\text { Prescribed }\end{array}$} & \multirow[t]{2}{*}{$\begin{array}{l}\text { Mucoid } \\
\text { Diarrhea }\end{array}$} & \multicolumn{2}{|c|}{$\begin{array}{l}\text { Antibiotics } \\
\text { Prescribed }\end{array}$} & \multirow[t]{2}{*}{$\begin{array}{l}\text { Bloody } \\
\text { Diarrhea }\end{array}$} & \multicolumn{2}{|c|}{$\begin{array}{l}\text { Antibiotics } \\
\text { Prescribed }\end{array}$} & \multicolumn{2}{|c|}{$\begin{array}{l}\text { Total } \\
\text { Antibiotics } \\
\text { Prescribed }\end{array}$} \\
\hline & & Yes & No & & Yes & No & & Yes & No & Yes & No \\
\hline$<5$ & 88 & 77 & II & 17 & 5 & 12 & 14 & 8 & 6 & 90 & 29 \\
\hline $5-12$ & 35 & 23 & 12 & 2 & 0 & 2 & I & 1 & 0 & 24 & 14 \\
\hline $12-65$ & 45 & 29 & 16 & 8 & 3 & 5 & 15 & 11 & 4 & 43 & 25 \\
\hline$>65$ & 4 & 3 & I & 0 & 0 & 0 & I & I & 0 & 4 & I \\
\hline Total & 172 & 132 & 40 & 27 & 8 & 19 & 31 & 21 & 10 & 161 & 69 \\
\hline
\end{tabular}

not require antibiotic treatment, about $77 \%$ (132) of them were treated with antibiotics inappropriately notifying the irrational use of antibiotics. Accordingly, the misuse of antibiotics in infectious such as acute diarrheal disease can lead to resistance, harmful eradication of normal flora, prolongation of illness (eg, superinfection with $C$. difficile), prolongation of carrier state (eg, delayed excretion of Salmonella), induction of Shiga toxins (eg, from Shiga toxin-producing E. coli), and increased cost. ${ }^{1,11}$

On the contrary, about 25\% (58) cases had clinical features of invasive bacterial-type (mucoid and bloody) that required antibiotics use, however, only about 50\% (29) of them were prescribed with antibiotics and was found lower than studies done elsewhere. ${ }^{12}$ Consequently, the remaining $50 \%$ of the patients had not received antibiotics which are still inconsistent with recommendations. ${ }^{1,13}$ The study showed almost comparable result with another study conducted in Bishoftu general hospital, Ethiopia, where only $28 \%$ of the antibiotics were appropriately prescribed. ${ }^{14}$

The study also revealed that under-five children were the most affected, about $52 \%$, age group by acute diarrheal disease and most antibiotics, $76 \%$, were also prescribed for these age groups. Nonetheless, medication (antibiotic) administration needs special attention for these age groups, antibiotics were still prescribed injudiciously. ${ }^{11}$ Despite researches and guidelines recommend the crucial role of zinc supplementation in treating and preventing acute diarrhea in children, particularly in developing countries, it was not prescribed totally.

The study showed that the extent of antibiotic use for the acute diarrheal disease was about $70 \%$ which is higher than the study conducted at central Region province where antibiotic use was about $27.4 \%{ }^{15}$ and lower than another study conducted in Southern Thailand where $73.8 \%$ of the cases showed antibiotics use for acute diarrheal disease. ${ }^{16}$

Cotrimoxazole was the most commonly prescribed drug followed by amoxicillin and then ciprofloxacin, as was the case in other studies done in Ethiopia and Thailand ${ }^{14,15}$ while other findings showed that norfloxacin and levofloxacin were the most commonly prescribed drugs. ${ }^{12,17}$ Cotrimoxazole and quinolones such as ciprofloxacin or levofloxacin have been the primary antibiotics of choice for most bacterial infections, ${ }^{18-20}$ although there is a growing resistance against these medications. ${ }^{21-23}$ Campylobacter spp.,Salmonellae, Neisseria gonorrhoeae, and Shigella spp. are notified by the world health organization as a list of fluoroquinoloneresistant bacteria that pose the greatest threat to human health and for which new antibiotics are desperately needed. This is a useful reminder of the danger of bacteria that are becoming resistant to antibiotics. ${ }^{8}$

Moreover, resistant organisms can quickly spread and so threaten communities with new strains of infectious disease that are more difficult to cure and more expensive to treat. Therefore, the ongoing explosion of antibioticresistant infections continues to be the global health care problem with an equally alarming decline in the research and development of new antibiotics to deal with the threat. $^{24,25}$ As a result, judicious use of antibiotics is recommended during the treatment of acute diarrheal disease so as to minimize the issue of antimicrobial resistance and associated problems. Taken together, the onset, duration, severity, and frequency of diarrhea should be noted, with particular attention to stool character (eg, watery, bloody, mucus-filled) while prescribing antibiotics for acute diarrheal disease.

Therefore, the study revealed that there is a high level of inappropriate antibiotics use which may fuel the 
increased antimicrobial resistance and associated costs nationally as well as globally. ${ }^{10,12}$ Moreover, this study determined the prevalence of antibiotics use, identifies the type of antibiotics used in the treatment of acute diarrheal disease and also assesses the adherence practice of prescribers to the standard treatment guidelines.

\section{Conclusion}

The study revealed that there is a high level of inappropriate antibiotic use for acute diarrheal disease in Chefa-robit health center. Cotrimoxazole, amoxicillin, and ciprofloxacin were the most prescribed antibiotics. Under-five children were the most affected age groups by acute diarrheal disease and most antibiotics were prescribed inappropriately for these age groups as well. Therefore, concerned bodies should provide training and awareness for prescribers regarding the management of acute diarrheal disease and the consequences of irrational antibiotics use.

\section{Data Sharing Statement}

Data are all contained within the manuscript.

\section{Ethical Consideration}

Ethical clearance was obtained from the College of Medicine and Health Sciences, Wollo University Institutional Review Committee (IRC), and permission was sought from CRHC. Confidentiality of the information was assured and privacy was maintained.

\section{Acknowledgments}

We would like to thank Wollo University for supporting this work.

\section{Author Contributions}

Both authors made substantial contributions to conception and design, acquisition of data, or analysis and interpretation of data; took part in drafting the article or revising it critically for important intellectual content; gave final approval of the version to be published; agreed on the journal to which the article will be submitted; and agree to be accountable for all aspects of the work.

\section{Funding}

The research was mainly funded by Wollo University.

\section{Disclosure}

The authors declare that they have no competing interests for this work.

\section{References}

1. WHO. Global Strategy for Containment of Antimicrobial Resistance: Executive Summary. Geneva: World Health Organization; 2001.

2. Jones TF, Bulens S, Gettner S, et al. Use of stool collection kits delivered to patients can improve confirmation of etiology in foodborne disease outbreaks. Clin Infect Dis. 2004;39(10):1454-1459. doi:10.1086/425319

3. Aranda-Michel J, Giannella RA. Acute diarrhea: a practical review. Am J Med. 1999;106(6):670-676. doi:10.1016/S0002-9343(99)00 $128-\mathrm{X}$

4. Control CfD, Prevention. Preliminary Food Net Data on the incidence of infection with pathogens transmitted commonly through food-10 states, 2008. MMWR Morb Mortal Wkly Rep. 2009;58 (13):333.

5. DuPont HL. Guidelines on acute infectious diarrhea in adults. Am J Gastroenterol. 1997;92(11).

6. Guerrant RL, Van Gilder T, Steiner TS, et al. Practice guidelines for the management of infectious diarrhea. Clin Infect Dis. 2001;32 (3):331-351. doi:10.1086/318514

7. De Bruyn G, Hahn S, Borwick A. Antibiotic treatment for travellers' diarrhoea. Cochrane Database Syst Rev. 2000;(3). doi:10.1002/ 14651858.CD002242.

8. Willyard C. The drug-resistant bacteria that pose the greatest health threats. Nat News. 2017;543(7643):15. doi:10.1038/nature.2017.21 550

9. Bai JC, Ciacci C. World gastroenterology organisation global guidelines: celiac disease February 2017. J Clin Gastroenterol. 2017;51 (9):755-768. doi:10.1097/MCG.0000000000000919

10. Shiferaw B, Solghan S, Palmer A, et al. Antimicrobial susceptibility patterns of Shigella isolates in foodborne diseases active surveillance network (foodnet) sites, 2000-2010. Clin Infect Dis. 2012;54 (suppl_5):S458-S63. doi:10.1093/cid/cis230

11. WHO. The Treatment of Diarrhea: A Manual for Physicians and Other Senior Health Workers. Geneva: WHO; 2005. WHO/CDD/ SER/80.2.2013

12. Hou F-Q, Sun X-T, Wang G-Q. Inappropriate use of empirical antibiotics in adults with acute infectious diarrhea in a large teaching hospital. J Chin Pharmaceut Sci. 2010;19:229-234.

13. Istúriz RE, Carbon C. Antibiotic use in developing countries. Infect Control Hosp Epidemiol. 2000;21(6):394-397.

14. Tulu S, Tadesse T, Alemayehu Gube A. Assessment of antibiotic utilization pattern in treatment of acute diarrhoea diseases in Bishoftu general hospital, Oromia Ethiopia. Adv Med. 2018;2018.

15. Howteerakul N, Higginbotham N, Dibley MJ. Antimicrobial use in children under five years with diarrhea in a central region province, Thailand; 2004.

16. Supcharassaeng S, Suankratay C. Antibiotic prescription for adults with acute diarrhea at King Chulalongkorn Memorial Hospital, Thailand. J Adv Med Med Res. 2011;94(5):545.

17. Kotwani A, Chaudhury RR, Holloway K. Antibiotic-prescribing practices of primary care prescribers for acute diarrhea in New Delhi, India. Value Health. 2012;15(1):S116-S9. doi:10.1016/j. jval.2011.11.008

18. Ericsson C, Johnson P, Dupont H, Morgan D, Jam B, De La Cabada FJ. Ciprofloxacin or trimethoprim-sulfamethoxazole as initial therapy for travelers' diarrhea: a placebo-controlled, randomized trial. Ann Intern Med. 1987;106(2):216-220. doi:10.7326/00034819-106-2-216

19. Ericsson CD, DuPont HL, Mathewson JJ. Optimal dosing of ofloxacin with loperamide in the treatment of non-dysenteric travelers' diarrhea. $J$ Travel Med. 2006;8(4):207. doi:10.2310/7060.2001.24244

20. Mattila L, Peltola H, Siitonen A, Kyrönseppä H, Simula I, Kataja M. Short-term treatment of traveler's diarrhea with norfloxacin: a double-blind, placebo-controlled study during two seasons. Clin Infect Dis. 1993;17(4):779-782. doi:10.1093/clinids/17.4.779 
21. Authority EFS, Prevention ECfD, Control. The European Union summary report on antimicrobial resistance in zoonotic and indicator bacteria from humans, animals and food in 2011. EFSA J. 2013;11(5):3196.

22. Ruiz J, Marco F, Oliveira I, Vila J, GascON J. Trends in antimicrobial resistance in campylobacter spp. causing traveler's diarrhea. Apmis. 2007;115(3):218-224.

23. Bennish ML, Salam MA, Khan WA, Khan AM. Treatment of shigellosis: III. Comparison of one-or two-dose ciprofloxacin with standard 5-day therapy: a randomized, blinded trial. Ann Intern Med. 1992;117(9):727-734. doi:10.7326/0003-4819-117-9-727
24. Khushal R. Prevalence, characterization and development of resistance pattern in indigenous clinical isolates against cephalosporins: Quaid-i-Azam University, Islamabad; 2004.

25. Cai Y, Wang R, Liang B, Bai N, Liu Y. Effectiveness and safety of tigecycline for the treatment of infectious disease: a systematic review and meta-analysis. Antimicrob Agents Chemother. 2010.

\section{Publish your work in this journal}

Drug, Healthcare and Patient Safety is an international, peer-reviewed open-access journal exploring patient safety issues in the healthcare continuum from diagnostic and screening interventions through to treatment, drug therapy and surgery. The journal is characterized by the rapid reporting of reviews, original research, clinical, epidemiological and post-marketing surveillance studies, risk management, health literacy and educational programs across all areas of healthcare delivery. The manuscript management system is completely online and includes a very quick and fair peer-review system. Visit $\mathrm{http}: / /$ www.dovepress.com/testimonials.php to read real quotes from published authors.

Submit your manuscript here: https://www.dovepress.com/drug-healthcare-and-patient-safety-journal 